\title{
Comparison between magnetic activated cell sorted monocytes and monocyte adherence techniques for in vitro generation of immature dendritic cells: an Egyptian trial
}

\author{
SALLY AHMED EL-SAHRIGY', NESRINE ALY MOHAMED ${ }^{2}$, HALA AHMED TALKHAN", \\ AZZA M. ABDEL RAHMAN ${ }^{I}$ \\ ${ }^{1}$ Pediatrics Medical Research Division, National Research Centre, Egypt \\ ${ }^{2}$ Clinical Pathology and Immunology Faculty of Medicine, Ain Shams University, Egypt
}

\begin{abstract}
Introduction: Dendritic cells (DCs) are the most efficient antigen presenting cells, which are considered a central component of the immune system for their extraordinary capacity to initiate and modulate the immune responses elicited upon recognition of infectious agents. This has made them a major focus of interest in the conception of immunotherapeutic vaccine strategies.

Aim of the study: To standardise a protocol for in vitro differentiation of human peripheral blood monocytes into immature DCs (iDCs) upon treatment with specific growth factors and to compare two monocyte isolation methods including magnetic activated cell sorted (MACS) monocytes by CD14+ immuno-magnetic beads and monocytes separated by adherence.

Material and methods: Immature DCs were generated from monocytes of human peripheral blood in the presence of granulocyte-macrophage colony-stimulating factor (GM-CSF) and interleukin (IL)-4 after in vitro culture for seven days. Cultured cells were stained with surface markers of iDCs: FITC-anti-CD14, PE-anti-CD11c, PE-anti-CDIa, PE-Cy5-anti-HLA-DR, and PE-anti-CD83 for flow cytometry analysis.

Results: We found that the viability of MACS-DCs was higher than DCs derived from monocytes separated by adherence (median 50 and interquartile range 45-50 vs. 25 and 10-30, respectively; $p<0.001)$. Flow cytometry analysis revealed that the median interquartile percentages of MACS-DCs expressing $C D 14^{-}$was significantly higher compared to the DCs derived from monocytes separated by adherence (median 80.2 and interquartile range 77.7-80.7 vs. 40.2 and 30.4-40.6, respectively; $p<0.001)$. However, MACS-DCs expressed the same levels of CD11c, CD1a, and HLA-DR as well as CD83 compared to the DCs derived from monocytes separated by adherence with $p$ value $>0.05$.

Conclusions: Both positively selected monocytes and monocytes separated by adherence procedure gave the same results as regards cell surface marker expression, although the DCs purity and viability using MACS separated monocytes were better.
\end{abstract}

Key words: adherence, cell separation, dendritic cell, phenotype.

(Centr Eur J Immunol 2015; 40 (1): 18-24)

\section{Introduction}

Immature dendritic cells (iDCs) play a crucial role in the surveillance of peripheral sites by migrating through all of the tissues and actively taking up foreign antigen [1]. They present antigens on major histocompatibility complex (MHC) class I and II molecules to T cells. In addition, they are equipped with a range of pathogen sensing molecules such as toll-like receptors (TLRs), nucleotide-binding oligomerisation domain proteins (NOD), and C-type lectins that allow them to detect pathogen products and sense inflammation [2]. The secretion of immunoregulatory cytokines such as interleukin (IL)-12 and type I interferon (IFN) are considered to be an early immune response critical for the polarisation of $\mathrm{CD} 14^{+}$

Correspondence: Nesrine Aly Mohamed, PhD, lecturer of Clinical Pathology and Immunology, Faculty of Medicine, Ain Shams University, Egypt, e-mail: alynesrine@yahoo.com 
T lymphocyte response towards a T helper pattern, a key process for the clearance of intracellular pathogens [3]. Moreover, dendritic cells (DCs) play a major part in transplant engraftment and rejection and in graft-versushost disease (GvHD). Preferentially tolerogenic or immunogenic DC subtypes offer targets for immunotherapy, to optimise transplant success rates and prolong disease-free and overall survival [4]. Advances in the extraction and in vitro culture of DCs have been a major driving force behind the increased interest in these cells and have facilitated the inclusion of these powerful adjuvants in therapeutic trials. Refined laboratory protocols are available for either the generation of DC from a number of readily available sources or for the direct isolation of DC from mixed cell populations [5]. Cells that have been found to yield DC, after culture in lineage-restricting cocktails of cytokines, include $\mathrm{CD} 34^{+}$stem cells and CD $14^{+}$monocytes. $\mathrm{CD} 14^{+}$monocytes are perhaps the most readily available precursors used to generate human DC, because they constitute $7-8 \%$ of human peripheral blood mononuclear cells (PBMCs) [6].

\section{Material and methods}

\section{Subjects}

Peripheral blood from fifty healthy voluntary blood donors was collected from the central blood bank at Ain Shams University Hospital. All of the donors were aged between twenty and forty years, of both sexes, and were found healthy in an orienting physical examination and all blood products were negative for common bloodborne pathogens, as detected by standard blood bank assays.

In the current study, 50 samples were cultured, but because of problems encountered during culture, only 35 samples were analysed. The 35 samples were subdivided into two groups: Group 1 included 20 samples in which DCs were derived from MACS monocytes. Group 2 included 15 samples in which DCs were derived from monocytes separated by adherence.

Twenty to fifty millilitres of citrate acid dextrose or heparinised anticoagulated fresh blood were aseptically collected in sterile 50-ml polypropylene centrifuge tubes. Samples were handled maximally within eight hours, and during this time period they were kept at room temperature.

The study was approved by the ethical committees of the National Research Centre, Dokki, Giza and Ain Shams University Hospital.

\section{Methods}

Cell culture is filled with variables that can make it difficult to determine the cause of problems. Narrowing a problem down to the one material or one critical procedure can be a daunting task. However, problems can usually be identified by carefully examining the symptoms and meticulously retracing each step in the culture process. Among the problems encountered were cell death in the culture by day 2 and contamination.

\section{Steps for generation of immature dendritic cells}

\section{Isolation of peripheral blood mononuclear cells}

Under complete aseptic conditions (laminar flow work area), the blood was diluted $1: 1$ with phosphate buffered saline (PBS) (Lonza, Walkersville, USA) without $\mathrm{Ca}^{2+}$ and $\mathrm{Mg}^{2+}$ (used in all following experiments). Peripheral blood mononuclear cells were isolated from buffy coats by Ficoll-Hypaque (Lonza) density-gradient centrifugation. The separated cells were washed twice in MACS buffer (Miltenyi Biotech, Germany). Then, cell pellets were suspended in $1 \mathrm{ml}$ MACS buffer then counted and tested for viability.

\section{Monocyte isolation from human peripheral blood}

\section{A. Monocyte purification by positive selection using CD14 microbeads}

Cell pellets were resuspended in a final volume of $80 \mu \mathrm{l}$ Magnetic Activated Cell Sorted (MACS) buffer and labelled with $20 \mu \mathrm{l}$ of microbeads with FITC (fluorescein isothiocyanate) conjugated mouse anti-human CD14 antibodies (Miltenyi Biotech).

The cells were mixed well and incubated at $4{ }^{\circ} \mathrm{C}$ for 15 minutes in the dark. After incubation, the cells were washed thrice with $500 \mu \mathrm{l}$ of MACS buffer by spinning at $300 \times \mathrm{g}$ for 10 minutes. The cells were resuspended in $1 \mathrm{ml}$ of buffer and used for magnetic sorting. The column was washed with $500 \mu \mathrm{l}$ of MACS buffer.

The magnetically labelled cells were passed through the column. The cells with magnetic microbeads were retained within the column and those that are unlabelled eluted out. The eluted fraction was collected as negative fraction. The column was washed thrice with $500 \mu \mathrm{l}$ of MACS buffer. Then the column was removed from the magnetic field.

The retained cells in the column were firmly flushed out by applying pressure on the matrix of the column by a plunger supplied with the kit. These were the positive fractions, which were washed twice with MACS buffer by spinning at $300 \times \mathrm{g}$ for 5 minutes and resuspended in $1 \mathrm{ml}$ of MACS buffer. Then the cells were tested for viability and counted.

\section{B. Monocyte purification by adherence separation}

Peripheral blood mononuclear cells were allowed to adhere to a six-well tissue culture plate $(3 \mathrm{ml} /$ well, Costar Corp., Cambridge, MA, USA) at a density of $2 \times 10^{6}$ cells/ $\mathrm{ml}$ in complete serum-free medium, which consisted of: $49.5 \mathrm{ml}$ of RPMI with L-glutamine 1640 (Lonza), $250 \mu \mathrm{l}$ amphotericin-B $(0.5 \%)$ (Biowest, Nuaillé, France), and $250 \mu \mathrm{l} \mathrm{penicillin/streptomycin}(0.5 \%)$ (Biowest), for three 
days at $37^{\circ} \mathrm{C}$ and $5 \% \mathrm{CO}_{2}$ in a fully humidified incubator. After that, non adherent cells were removed by aspiration and the flask was washed extensively twice with warm media, and the remaining adherent cells (monocytes) were removed by gentle scraping using a sterile cell scraper, and the flask was shaken then washed to help the complete detachment of the cells. Inverted microscopic examination of adherent monocytes showed small clusters of round cells with some cytoplasmic processes occasionally extending from them.

Cells were centrifuged at $1200 \mathrm{rpm}$ for 10 minutes and resuspended in $1 \mathrm{ml}$ of MACS buffer, and then they were counted and tested for viability.

\section{Cell culture}

Monocyte-derived DCs (MoDCs) were generated by culturing monocytes in six-well tissue culture plates $(3 \mathrm{ml} /$ well) with $50 \mathrm{ng} / \mathrm{ml} \mathrm{GM-CSF}$ and $20 \mathrm{ng} / \mathrm{ml} \mathrm{IL-4} \mathrm{(R \& D}$ systems, Minneapolis, USA), for seven days at $0.5 \times 10^{6}$ cells/ml in RPMI 1640, supplemented with $2 \mathrm{mM} \mathrm{L-glu-}$ tamine, $15 \%$ foetal calf serum (FCS) (Biowest) together with $10 \mu \mathrm{g} / \mathrm{ml}$ penicillin/streptomycin, $1 \mu \mathrm{g} / \mathrm{ml}$ amphotericin $\mathrm{B}, 0.1 \mathrm{mM}$ non essentials amino acids, $1 \mathrm{mM}$ sodium pyruvate, and $50 \mu \mathrm{M} 2$-mercaptoethanol at $37^{\circ} \mathrm{C}$ in $5 \% \mathrm{CO}_{2}$ humidified air.

Every 2-3 days, the medium was examined with an unaided eye to look for signs of microbial contamination (turbid culture media, change in the colour of the media, change in the growth rates, abnormally high $\mathrm{pH}$ and poor attachment). Then they were examined by the inverted phase contrast microscope (100 to 200x) for assessment of the cell condition (viable cells were round, bright and refractile) and morphology. Vacuolisation and cell lysis are signs of microbial contamination.

Additionally, every 2-3 days, the cultures were fed with fresh medium and cytokines to keep the cells healthy and actively growing, and cell viability assay was done as we changed the medium.

Monocytes cultured in the presence of GM-CSF and IL-4 acquired characteristic colony morphology. They were found to have confluent appearance, which was the result of both an increase in cell size and de novo proliferation, as evidenced by an increase in cell number.

Non-adherent cells, thereafter called monocyte-derived DCs, were harvested at day 7 , and were then tested for viability.

\section{Cell viability assay}

Trypan blue dye exclusion test was done by the method of Rosenberg et al. [7]. The test is based on microscopic examination of trypan blue staining: viable cells are unstained, and dead cells contain the dye. Trypan blue solution and cell suspension were mixed in the ratio of $1: 1$. Then the cells were observed under microscope and counted. The percentage of viable cells was calculated as the number of viable cells divided by the total number of cells (viable + dead cells $) \times 100$.

\section{Flow cytometry}

Cell populations from each respective sample were washed with PBS and centrifuged at $1500 \mathrm{~g}$ (3200 rpm) for 3 minutes. After removing all but $1 \mathrm{ml}$ of the supernatant, cells were resuspended. $100 \mu \mathrm{l}$ cell suspensions were added to fluorochrome-conjugated reagents: FITC-anti-CD14, PE-anti-CD11c, PE-anti-CD1a, PE-Cy5-anti HLA-DR, and PE-anti-CD83 (Beckman Coulter, Marseille, France). Then the cells were incubated in the dark for 15 minutes after light vortexing. Stained cells were analysed by flow cytometry. Data acquisition and analysis were performed on an EPICS XL flow cytometer (Coulter Electronics, Florida, USA) using SYSTEM II version 3 software with a standard three-colour filter configuration. Cells were initially gated out on the basis of forward scatter (size) and side scatter (complexity). The initially gated cells were further analysed for CD14 and CD1a, HLA-DR, CD11c, and CD83expression.

\section{Statistical analysis}

Statistical analysis was performed using IBM SPSS statistics (V. 21.0, IBM Corp., USA, 2012). Data were expressed as mean \pm SD for quantitative parametric measures in addition to median percentiles for quantitative non-parametric measures and both number and percentage for categorised data. The Mann-Whitney test was used for comparison between two independent groups for non-parametric data. The independent $t$-test was used for comparison between two independent groups for parametric data. A $p$ value $<0.05$ indicated statistical significance while $p<0.01$ and 0.001 indicated high statistical significance.

\section{Results}

The mononuclear cells obtained from the fresh blood samples were tested for cell count and viability, where the cell count ranged from 1.5 to $5.0 \times 10^{7}$ cells $/ \mathrm{ml} \mathrm{ac-}$ cording to the blood volume used, and the viability was $95-98 \%$.

\section{Monocytes separated by adherence}

The cell count ranged from 5 to $15 \times 10^{5}$ cells $/ \mathrm{ml}$, while the viability ranged between $70 \%$ and $75 \%$. Cells were also examined using Leishman stain, which clearly identified these cells as monocytes (Fig. 1).

\section{Magnetic activated cell sorted separated monocytes}

The cell count ranged between 4 and $9 \times 10^{6}$ cells $/ \mathrm{ml}$, while the viability ranged between $90 \%$ and $95 \%$. 


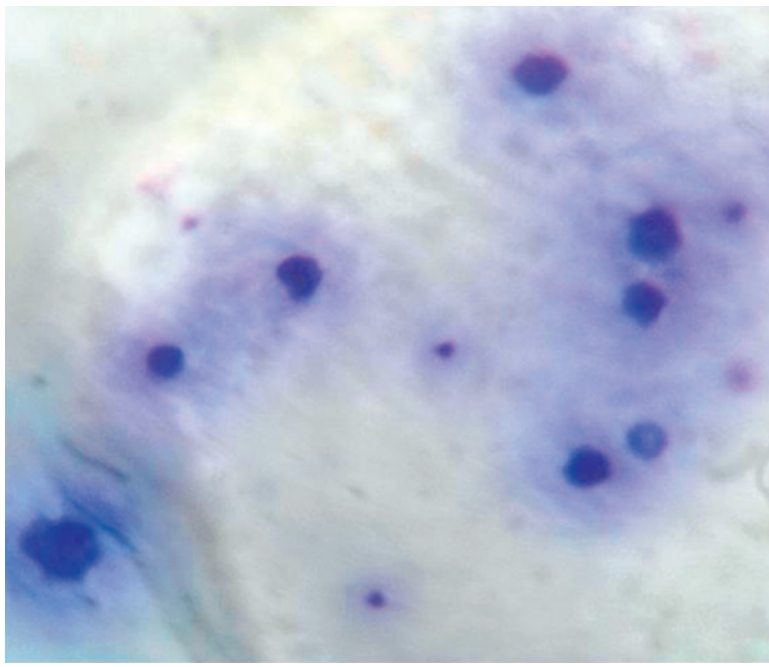

Fig. 1. Morphology of purified monocytes stained by Leishman stain

Living cells decreased gradually during the time course of culture as seen by the inverted microscope. On day 7 , the non-adherent cells in the differentiation culture were harvested and stained with surface markers of iDCs for flow cytometry analysis. Viability was assessed and it was found that the median (IQR) percentage of MACS-DCs viability was significantly higher than that of DCs derived from monocytes separated by adherence (median 50 and interquartile range $45-50$ vs. 25 and 10-30, respectively; $p<0.001$ ) (Fig. 2).

Immunophenotypical analysis of iDCs revealed that the median interquartile percentages of MACS-DCs ex-

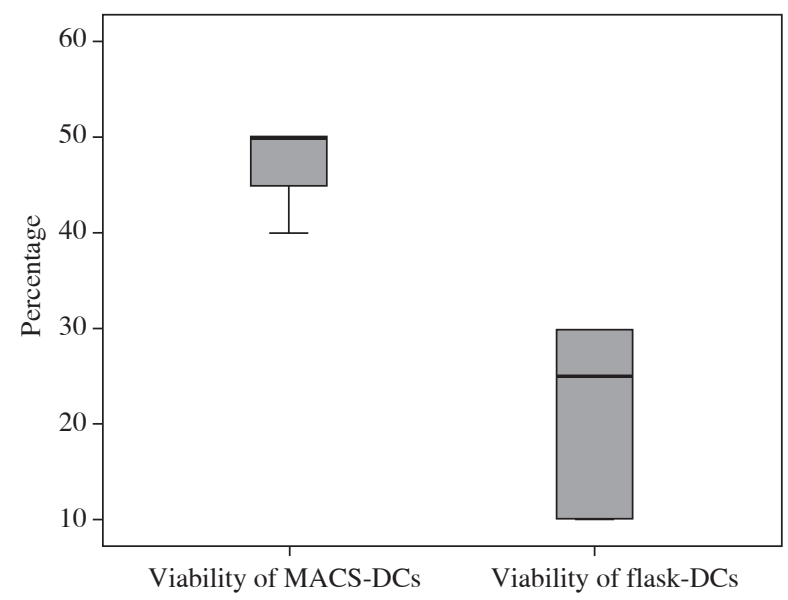

Fig. 2. Comparison between MACS-DCs and Flask-DCs as regards viability

pressing $\mathrm{CD} 14^{-}$was significantly higher compared to the DCs derived from monocytes separated by adherence (median 80.2 and interquartile range 77.7-80.7 vs. 40.2 and 30.4-40.6, respectively; $p<0.001)$. However, MACS-DCs expressed the same levels of CD11 $\mathrm{c}^{+}, \mathrm{CD} 1 \mathrm{a}^{+}$, and HLA$\mathrm{DR}^{+}$as well as $\mathrm{CD} 83^{+}$compared to the DCs derived from monocytes separated by adherence with $p$ value $>0.05$ (Table 1).

Figure 3 shows an example of the flow cytometry charts performed in our study for analysis of immature DCs phenotype after culture of MACS separated monocytes.

Table 1. Phenotypic comparison MACS-DCs and DCs derived from monocytes separated by adherence

\begin{tabular}{|c|c|c|c|c|}
\hline & $\begin{array}{l}\text { Immature dendritic cells } \\
\text { derived from MACS } \\
\text { separated monocytes } \\
\text { (no of samples }=20 \text { ) }\end{array}$ & $\begin{array}{l}\text { Immature dendritic cells derived } \\
\text { from monocytes } \\
\text { separated by adherence } \\
(\text { no of samples }=15)\end{array}$ & $\mathbf{t}^{*} / \mathbf{z}^{*}$ & $p$ value \\
\hline CD14- cells & $80.2(77.7-80.7)$ & $40.2(30.4-40.6)$ & $-4.402 *$ & 0.000 (HS) \\
\hline CD14-/CD11 ${ }^{+}$cells & $8.5(8.1-9.5)$ & $8.3(8.1-9.6)$ & $-0.243^{*}$ & $0.808(\mathrm{NS})$ \\
\hline CD14-/HLA-DR ${ }^{+}$cells & $3.5(3.2-4.2)$ & $3.8(3.4-7.4)$ & $-0.869^{*}$ & $0.385(\mathrm{NS})$ \\
\hline $\mathrm{CD} 14-/ \mathrm{CD} 11 \mathrm{c}^{+} / \mathrm{HLA}-\mathrm{DR}^{+}$cells & $86.74 \pm 2.41$ & $87.53 \pm 1.83$ & $-0.910^{\circ}$ & $0.371(\mathrm{NS})$ \\
\hline $\mathrm{CD} 14-/ \mathrm{CD} 1 \mathrm{a}^{+}$cells & $3.83 \pm 1.34$ & $3.42 \pm 1.04$ & $-0.033^{\circ}$ & $0.956(\mathrm{NS})$ \\
\hline CD14-/HLA-DR + CD83+ & $3.19 \pm 0.58$ & $3.20 \pm 0.64$ & $-0.043^{\bullet}$ & $0.966(\mathrm{NS})$ \\
\hline
\end{tabular}


A

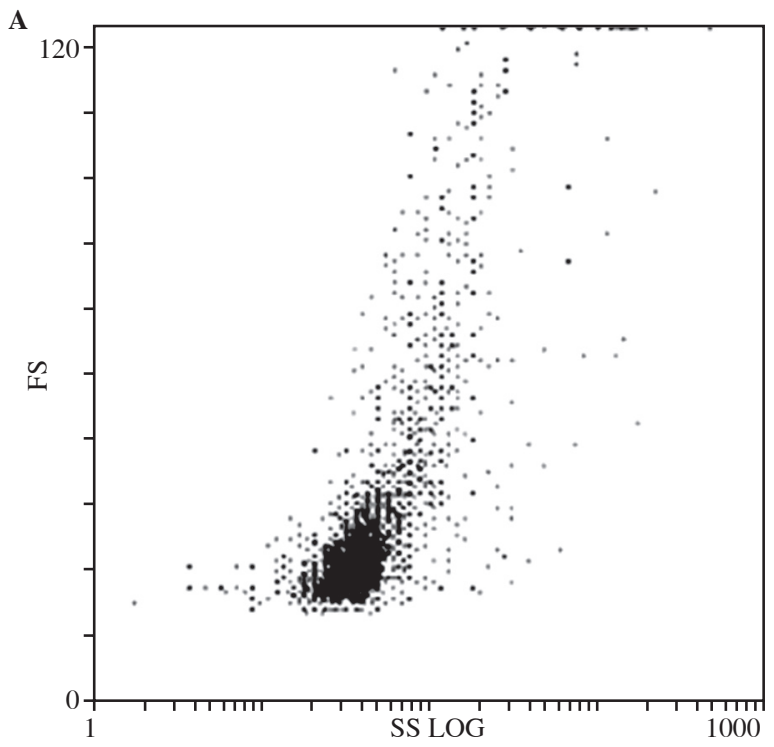

$\mathbf{C}_{1000}$

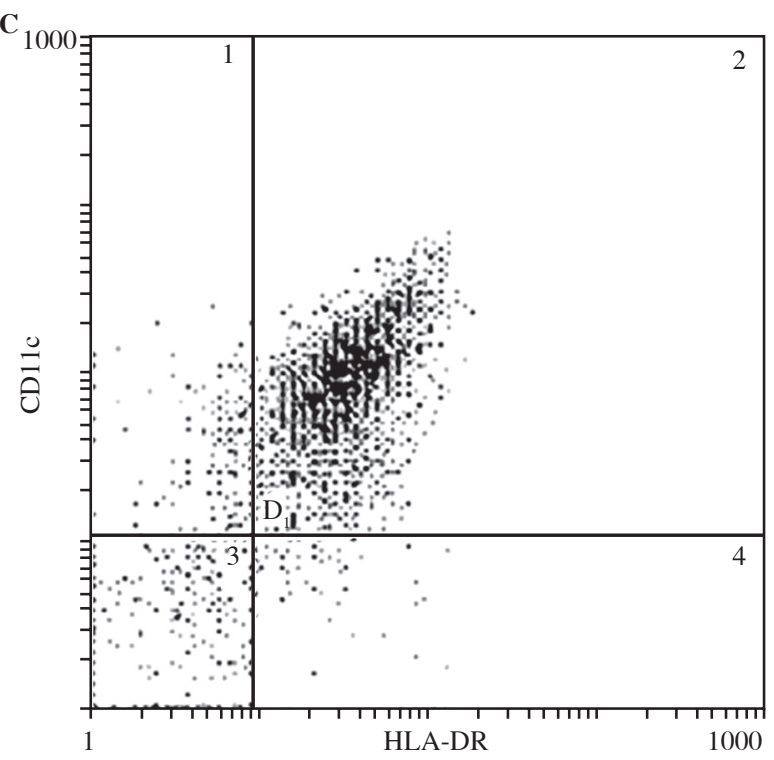

B
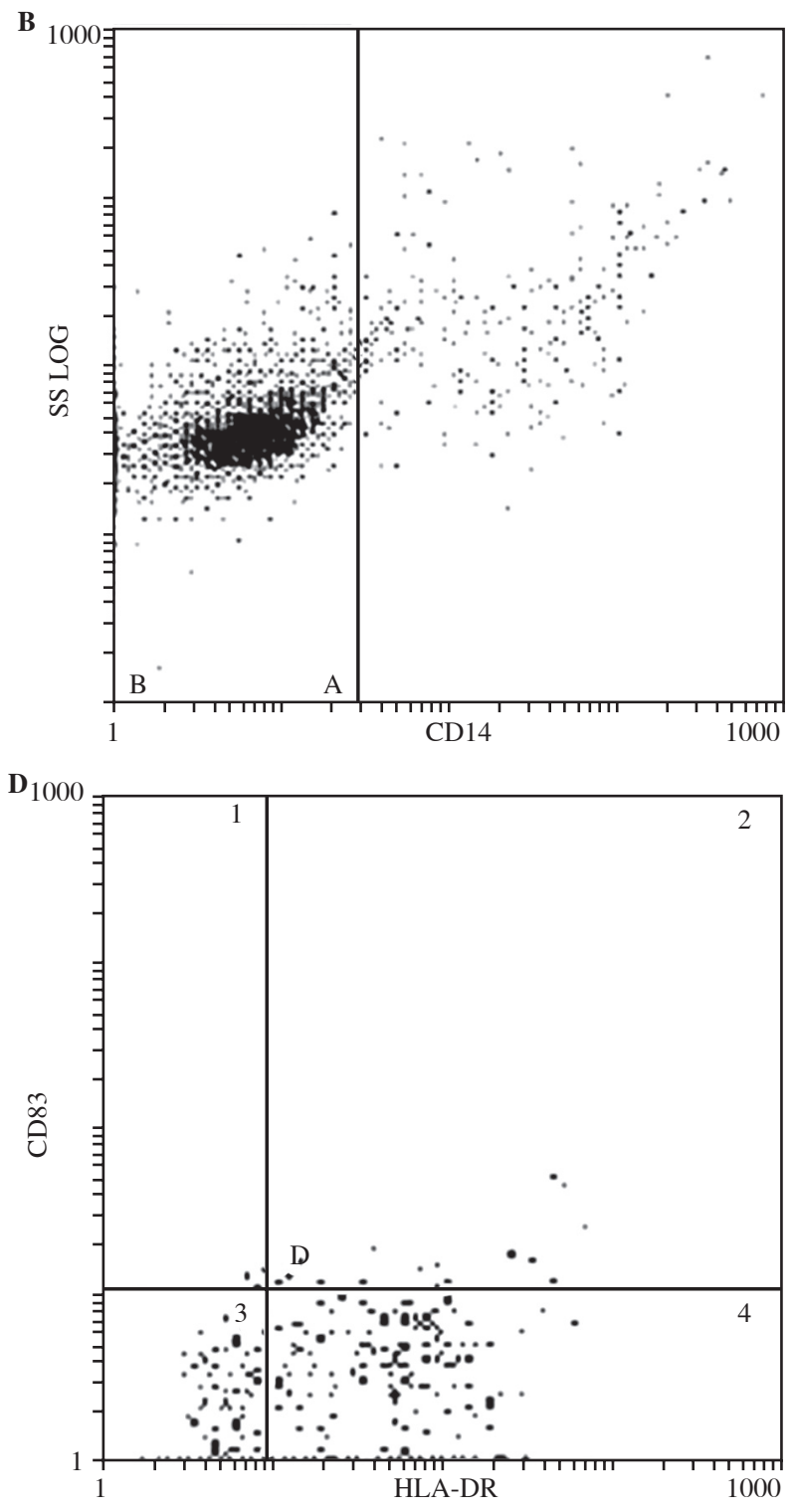

Fig. 3. Phenotype of DC generated after culture of MACS separated monocytes. Dead cells were excluded by gating on forward and side scatter properties, and the remaining viable cells were analysed. Representative dot plots of FCM and the gating strategy used: A) shows forward and side scatters to gate monocytes; B) shows CD14- cells were acquired after gating the monocytes population by forward and side scattered properties; C) gating approach for discrimination of CD14CD11 $\mathrm{c}^{+} \mathrm{HLA}_{-\mathrm{DR}}^{+}$populations; D) gating approach for discrimination of CD14- $\mathrm{HLA}^{-\mathrm{DR}^{+}} \mathrm{CD}^{-} 3^{-}$populations

\section{Discussion}

Researches hold great promise for DCs in the development of cancer immunotherapies as well as the treatment of autoimmune diseases. Dendritic cells also play an essential role in the setting of HIV infection and the pathogenesis of several other viruses, and thus can be used as a therapeutic target. Therefore, a requirement for the development of a standardised DC generation protocols needed to provide 'reference dendritic cells' to which other dendritic cells could be compared [8].

Currently, there are two known major subsets of DCs in humans: Lymphoid DCs derived from plasmacytoid cells in blood, and myeloid DCs that arise from the myeloid precursor; and peripheral blood monocytes or CD34 progenitors from bone marrow. The most commonly used cell type for DC generation are peripheral blood mono- 
cytes, as the generation of $\mathrm{CD} 34^{+}$precursor-derived DCs requires a more substantial cocktail of cytokines, in addition to the need for extensive purification of CD34 precursor cells from leukapheresis products [9].

This is a preliminary study to establish a protocol for obtaining iDCs from peripheral blood monocytes in our laboratory.

There are multiple methods for obtaining monocytes as abundant and simply available cells in the peripheral blood. Some of these methods include plastic/glass adherence [10], density gradient centrifugation [11], and specific marker-based separations such as magnetic activated cell sorting, fluorescent activated cell sorting (FACS), and bipolar tetrameric antibody (Ab)-based separation [12]. In this study, the effects of two monocyte separation methods including MACS and cell culture flask adherence methods were compared regarding the production of DCs by several phenotypic analyses. The MACS method is based upon a monocyte-specific marker, i.e. CD14, and the cell culture flask adherence method is based upon the fact that $\beta 2$ integrin expressing cells can adhere to plastic or glass [13]. In this study, the expression of CD11c, HLA-DR, CD83, and CD1a was the same regardless of the method used to isolate the original CD14+ cells. However, the MACS method is rapid and produces cell populations with high viability and purity, compared to monocytes separated by adherence method. These results were in partial agreement with Delirezh and Shojaeefar [13]. They demonstrated that the viability of MACS-DCs was slightly higher than FlaskDCs and that they express higher levels of CD14 ${ }^{-}$in comparison to Flask-DCs. In contrast to our results, they revealed that MACS-DCs expressed higher levels of CD83+ and HLA-DR ${ }^{+}$compared to the Flask-DCs. Induction of $\mathrm{T}$ cell proliferative responses was higher in Flask-DCs and they also elicited higher levels of IL-12 : IL-10 and IFN- $\gamma$ : IL-4 ratios in cytokine generation assays. However, they recommended further work to study the impact of both methods on the subsequent function of DC. Therefore, we started to study the kinetics of monocyte differentiation into DCs to determine the optimum time at which we can obtain immature DCs with the best viability, this was accomplished through staining the cells with surface markers of immature DCs: CD14, CD11c, CD1a, HLA-DR, and CD83 monoclonal antibodies for flow cytometry analysis every two days.

Within the human blood, DCs are lineage (CD3, CD14, CD19, CD56) negative and HLA-DR positive [14]. The CD1a molecule is considered a specific marker of immature DCs [15]. In this study, however, CD 1a was only expressed on a small percentage of iDCs $(0.2 \%)$ generated from peripheral blood monocytes. On the other hand, $87.5 \%$ were $\mathrm{CD}_{14}^{-} \mathrm{HLA}^{-} \mathrm{DR}^{+} \mathrm{CD} 11 \mathrm{c}^{+}$. This was in agreement with Osada et al. [14], who stated that MoDCs are CD $11 \mathrm{c}^{+}$CD14- ${ }^{-} \mathrm{HLA}^{-} \mathrm{DR}^{+}$with a fraction being CD1a ${ }^{+}$, while DCs generated from $\mathrm{CD} 34^{+}$haematopoietic stem

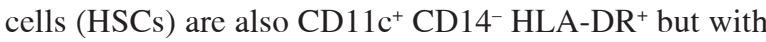
a greater percentage of them being $\mathrm{CD} 1 \mathrm{a}^{+}$. The results of this study were also in agreement with Osugi et al. [16], who found that the Mo-DCs derived after seven days in vitro culture lacked CD1a antigen, as reported in 21 out of 24 experiments, but expressed HLA-DR. However, in a study done by Angelini et al. [17] myeloid DCs were defined as CD14 ${ }^{-}, \mathrm{CD}_{1} \mathrm{a}^{+}$, and CD11 $\mathrm{c}^{+}$. Colić et al. [18] defined iDCs by the expression of CD1a, CD80, CD86, and HLA-DR with down-regulation of CDI4 and the absence of CD83. Elkord et al. [19] demonstrated that iDCs are phenotypically different from their monocyte precursors. They express lower levels of CD14 and higher levels of HLADR and CD86. Immature dendritic cells express CD1a and low levels of CD80, but do not express CD83. Kolli et al. [20] also confirmed DC phenotype by flow cytometry for other surface markers, including CD11b, CD11c, MHC class II, CD80, and CD86. Dzionek et al. [21] found that BDCA-2 and BDCA-4 are expressed on CD11c - CD123bright plasmacytoid dendritic cells, which are immature dendritic cells. Others identified dendritic cells as being CD45+CD3-CD14- 16- 19- 20- 56- HLA-DR bright [22]. In a study done by Tkachenko et al. [15] the following culture media were used: RPMI 1640 supplemented with $2 \%$ human serum albumin; RPMI 1640 supplemented with $2 \%$ TCH serum replacement; X-VIVO 15; and Panserin 501. Flow cytometry analysis revealed that in all media iDC cells were $\mathrm{CD} 45^{+} \mathrm{CD} 83^{+}$and lost CD14. They used the following panel to identify iDCs: CD14-CD1a ${ }^{+}, \mathrm{CD}_{4} 5^{+}$, $\mathrm{CD}^{+} 0^{+}, \mathrm{CD}^{+} 6^{+}$, and $\mathrm{CD} 83^{+}$.

In the present study, iDCs were generated by culturing monocytes with $10 \mathrm{ng} / \mathrm{ml} \mathrm{IL-4} \mathrm{and} 50 \mathrm{ng} / \mathrm{ml} \mathrm{GM-CSF} \mathrm{[1].}$ Other researchers used different concentrations of growth factors and yet their attempts were successful as regards DC yield. These concentrations were as follows: $100 \mathrm{ng} /$ $\mathrm{ml} \mathrm{GM-CSF}$ and $20 \mathrm{ng} / \mathrm{ml} \mathrm{IL-4} \mathrm{[23],} 10 \mathrm{ng} / \mathrm{ml} \mathrm{GM-CSF}$ and $20 \mathrm{ng} / \mathrm{ml} \mathrm{IL-4} \mathrm{[24],} 100 \mathrm{ng} / \mathrm{ml}$ GM-CSF and $20 \mathrm{ng} / \mathrm{ml}$ IL-4 Kolli [20] and $50 \mathrm{ng} / \mathrm{ml} \mathrm{GM-CSF}$ and $50 \mathrm{ng} / \mathrm{ml} \mathrm{IL-4}$ Stocki [25].

As regards antibiotics, some researchers recommended not using antibiotics in the culture medium because this may lead to the appearance of antibiotic-resistant strains [1]. Consequently, at the start of the study, antibiotics were not added to the culture medium, but contamination occurred. So penicillin/ streptomycin as well as Amphotericin B were added to the culture media in this study. Also, copper sulphate was used, as records demonstrate that copper can inhibit the growth of many different microorganisms, by using it in the $\mathrm{CO}_{2}$ incubator [26]

The results of the study revealed that the anticoagulant used for blood collection (citrate or heparin) did not affect monocyte differentiation into DCs. Aiba et al. [27] and Tkachenko et al. [15] used heparin, Facci et al. [28] used EDTA while Giacomini et al. [1] used citrate. Their studies showed similar results as regards DC yields. 


\section{Conclusions}

In conclusion, the present study is a preliminary trial for the generation of immature MoDCs in vitro. Positively selected blood monocytes and those selected by adherence gave the same results as regards cell surface marker expression although the viability and purity of MACS-separated monocytes were better. In addition, the use of a panel of surface markers for identification of in vitro generated dendritic cells is highly recommended. Further studies are recommended for the study of kinetics of monocyte differentiation into DCs. Also, further maturation of iDCs generated from peripheral blood monocytes using tumor necrosis factor $\alpha$ (TNF- $\alpha$ ), LPS, or CD40L is recommended for further use of mature DCs in DC vaccines for cancer therapy as well as for the treatment of some infectious diseases. In the current study, unfortunately, we did not compare both methods on the blood from one donor. This point should be considered in future studies to make the comparison more accurate.

\section{The authors declare no conflict of interest. \\ The practical part of this work was funded by research grant number $S 90501$ offered by the National Research Centre.}

\section{References}

1. Giacomini E, Remoli ME, Gafa V, et al. (2009): IFN- $\beta$ improves BCG immunogenicity by acting on DC maturation. J Leukoc Biol 85: 462-468.

2. Randolph GJ, Ochando J, Partida-Sanchez S (2008): Migration of dendritic cell subsets and their precursors. Annu Rev Immunol 26: 293-316.

3. Kaiko GE, Foster PS (2011): New insights into the generation of Th2 immunity and potential therapeutic targets for the treatment of asthma. Curr Opin Allergy Clin Immunol 11: 39-45.

4. Pereira M, Paiva A (2011): Dendritic cells in cord blood transplantation: a review. Stem Cells Int 11: 39-45.

5. Tosi D, Valenti R, Cova A, et al. (2004): Role of cross-talk between IFN-alpha-induced monocyte-derived dendritic cells and NK cells in priming CD8+ T cell responses against human tumor antigens. J Immunol 172: 5363-5370.

6. Almezel BS (2010): Generation of monocyte-derived dendritic cells for adoptive Immunotherapy. J Immunol 188: 3363-3370.

7. Rosenberg IL, Russel CW, Giles GR (1978): Cell viability studies on the exfoliated colonic cancer cell. Br J Surg 65: 188-190.

8. Erdmann M, Schuler-Thurner B (2010): Towards a standardized protocol for the generation of monocyte-derived dendritic cell vaccines. Methods Mol Biol 595: 149-163.

9. Rozis G, Benlahrech A, Duraisingham S, et al. (2008): Human langerhans' cells and dermal-type dendritic cells generated from CD34 stem cells express different toll-like receptors and secrete different cytokines in response to toll-like receptor ligands. Immunol 124: 329-338.

10. Davis GE (1992): The Mac-1 and p150/95 beta 2 integrins bind denatured proteins to mediate leukocyte cell-substrate adhesion. Exp Cell Res 200: 242-252.

11. Lehner M, Holter W (2002): Endotoxin-free purification of monocytes for dendritic cell generation via discontinuous density gradient centrifugation based on diluted Ficoll-Paque Plus. Int Arch Allergy Immunol 128: 73-76.

12. Mucci I, Legitimo A, Compagnino M, et al. (2009): The methodological approach for the generation of human dendritic cells from monocytes affects the maturation state of the resultant dendritic cells. Biologicals 37: 288-296.

13. Delirezh N, Shojaeefar E (2012): Phenotypic and functional comparison between flask adherent and magnetic activated cell sorted monocytes derived dendritic cells. Iran J Immunol 9: 98-108.

14. Osada T, Clay TM, Woo CY, et al. (2006): Dendritic cellbased immunotherapy. Int Rev Immunol 25: 377-413.

15. Tkachenko N, Wojas K, Tabarkiewicz J, Rolinski J (2005): Generation of dendritic cells from human peripheral blood monocytes - comparison of different culture media. Folia Histochem Cytobiol 43: 25-30.

16. Osugi Y, Vuckovic S, Hart DN (2002): Myeloid blood CD11c dendritic cells and monocyte-derived dendritic cells differ in their ability to stimulate T lymphocytes. Blood 100: 2858-2866.

17. Angelini F, Pacciani V, Corrente S, et al. (2011): Dendritic cells modification during sublingual immunotherapy in children with allergic symptoms to house dust mites. World J Pediatr 7: 24-30.

18. Colić M, Jandrić D, Stojić-Vukanić Z, et al. (2003): Differentiation of human dendritic cells from monocytes in vitro using granulocyte-macrophage colony stimulating factor and low concentration of interleukin-4. Vojnosanit Pregl 60: 531-538.

19. Elkord E, Paul EW, Howard K, Anthony WR (2005): Human monocyte isolation methods influence cytokine production from in vitro generated dendritic cells. Immunology 114: 204-212.

20. Kolli D, Bao X, Liu T, et al. (2011): Human metapneumovirus glycoprotein $\mathrm{G}$ inhibits TLR4-dependent signaling in monocyte-derived dendritic cells. J Immunol 187: 47-54.

21. Dzionek A, Fuchs A, Schmidt P, et al. (2000): BDCA-2, BDCA-3, and BDCA-4: three markers for distinct subsets of dendritic cells in human peripheral blood. J Immunol 165: 6037-6046.

22. Miyazaki S, Tsuda H, Sakai M, et al. (2003): Predominance of Th2-promoting dendritic cells in early human pregnancy decidua. J Leukoc Biol 74: 514-522.

23. Zobywalski A, Javorovic M, Frankenberger B, et al. (2007): Generation of clinical grade dendritic cells with capacity to produce biologically active IL-12p70. J Transl Med 5: 18-22.

24. Jiang M, Osterlund P, Sarin LP, et al. (2011): Innate immune responses in human monocyte-derived dendritic cells are highly dependent on the size and the 5' Phosphorylation of RNA molecules. J Immunol 187: 1713-1721.

25. Stocki P, Wang XN, Dickinson AM, et al. (2012): Inducible heat shock protein 70 reduces $\mathrm{T}$ cell responses and stimulatory capacity of monocyte-derived dendritic cells. J Biol Chem 287: 12387-12394.

26. El-Danasouri ID, Schroen (2009): Preventing cell culture contamination with copper $\mathrm{CO} 2$ incubators. ThermoFisherScientific. ANCO2PRECON0809.

27. Aiba S, Manome H, Yoshino Y, Tagami H (2000): In vitro treatment of human transforming growth factor- $\beta$-treated monocyte derived dendritic cells with haptens can induce the phenotypic and functional changes similar to epidermal langerhans cells in the initiation phase of allergic contact sensitivity reaction. Immunology 101: 68-75.

28. Facci M, Auray G, Buchanan R, et al. (2010): A comparison between isolated blood dendritic cells and monocyte derived dendritic cells in pigs. Immunology 129: 396-405. 